\title{
The design and feasibility test of drive-thru market prototype based on Wemos as the learning media of internet of things (IOT) application
}

\author{
Rustam Asnawi ${ }^{1 *}$, Ariadie Chandra Nugraha ${ }^{1}$, Deny Budi Hertanto ${ }^{1}$, Faranita Surwi ${ }^{1}$, Indriya Galih \\ Prayogi ${ }^{1}$ \\ ${ }^{1}$ Department of Electrical Engineering Education, Faculty of Engineering, Universitas Negeri Yogyakarta, 55281 Yogyakarta, Indonesia \\ *E-mail: rustam@uny.ac.id \\ * corresponding author
}

This research aims at (1) developing a learning media for the internet of things (IoT) applications in the form of Wemos-based drive-thru market module which is appropriate for Interface Engineering Courses at Electrical Engineering Education, Faculty of Engineering, Universitas Negeri Yogyakarta; and (2) determining the feasibility of the developed learning media. The subject of the research was the 2015 Mechatronics Engineering Education students. The object of the research was the drive-thru market prototype. The research instrument was the questionnaire to obtain data on media feasibility. The proper research results were in the form of (1) the hardware namely the drive-thru market prototype and it's Android application software, (2) the proper function of the prototype and Android applications with the design, (3) the feasibility from the media experts with the percentage of 78\% and 83 $\%$ respectively that can be categorized as Appropriate, and from the user obtained the percentage of $86.15 \%$ with the category of Very Appropriate.

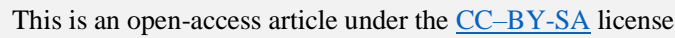

\author{
Article history \\ Received: \\ 30 September 2020 \\ Revised: \\ 14 October 2020 \\ Accepted: \\ 14 October 2020 \\ Keywords \\ Wemos, \\ Drivethru market \\ Internet of things \\ Android application
}

\section{Introduction}

Internet of Things (IoT) is an architecture consisting of hardware components, software systems, APIs Web, protocols that mutually perform certain tasks with an internet connection, for example, through the internet sensor data can be accessed and control systems can be driven. Several components that can be used to support the implementation of IoT include a microcontroller and an additional module for internet access. The microcontroller, in this case, is used as the controller of the electronic circuit. Many types of additional modules can be used for internet access including Ethernet Shield, SIM 900A Modem, and ESPN 8266 wifi. The keep growing microcontroller is the one that has been integrated with ESPN 8266 wifi called Wemos. The advantages of Wemos include 
Journal of Engineering and Applied Technology

Vol. 1, No. 1, March 2020, pp. 11-20

cheaper prices, better form, and faster internet access compared to microcontroller-based wireless systems, such as SIM 900A Modems.

The microcontroller has also been one of the main subjects in the Mechatronics Engineering Education Study Program, Department of Electrical Engineering Education, Faculty of Engineering, Universitas Negeri Yogyakarta. This study program has a vision in 2024 to be a superior study program at the international level in the field of mechatronics engineering education to produce competent graduates who are devout, independent, and intellectual in the Mechatronics engineering education field. Currently, the Mechatronics Engineering Education Study Program has accommodated the development of IoT technology in the Semester Learning Plan of the Interface Engineering course. Interface Engineering courses are practice learning that studies techniques to connect computers with electronic devices such as microprocessors, microcontrollers, sensors, and actuators. The Interface Engineering practice course aims to facilitate the students to have competence in implementing interface protocols that are commonly used, i.e. IEEE 1284 (Parallel Port), R232 (Asynchronous Serial communication Port), USB, microcontroller, sensors, actuators, and IoT to read the input data from the sensor and write down data or commands on the actuator.

The Interface Engineering course is a relatively new subject that contains some weakness because of the inadequate material that has not been able to support the IoT understanding. It triggers low learning quality. Thus, it is necessary to improve the learning system of the Interface Engineering course, especially on IoT and Android applications to support IoT. Based on the Interface Engineering Semester Learning Plan, this course should contain material about IoT and the Android application supporting IoT. but based on the results of observations, interviews with lecturers, in the learning process Interface Engineering has not obtained maximum results that meet the targets and learning objectives. There is a need for media that can help achieve learning objectives as expected in the Semester Learning Plan for Interface Engineering courses.

Based on the semester learning plan of Interface Engineering, this course should contain materials about IoT and the Android application to support IoT. However, based on the results of observations, and interviews with lecturers, the learning process of this course has not met the learning objectives. It shows the urgency of the learning media that can help to achieve the learning goals. By having creative and innovative learning media like programming in the field of industrial automation, the goals of the Interface Engineering learning can be achieved more effectively.

In the Industrial Automation System Planning course at Mechatronics Engineering Education Study Program, Department of Electrical Engineering Education, Universitas Negeri Yogyakarta, there is an interesting learning media about industrial automation and IoT, namely the drive-thru market prototype. This system allows car or motorcycle drivers to enter some partitions containing shopping items like in the market. The drivers only need to press the button on the rack to rotate it and choose the items they want. The selected item is then placed on the conveyor and the goods will arrive at the cashier, then the drivers go to the cashier to pay for the goods. The drive-thru market has already used IoT technology that can display the availability of goods to consumers through their Android smartphone. The type of microcontroller used in the drive-thru market prototype is Arduino and wemos. Arduino is an electronic board containing an Atmega328 microcontroller [3]. There are 
Journal of Engineering and Applied Technology

Vol. 1, No. 1, March 2020, pp. 11-20

many advantages of Arduino where it does not require an external flash programmer. The Arduino microcontroller chip is loaded with a bootloader that makes the uploading process simpler. Meanwhile, wemos is an Arduino UNO-like microcontroller that has been integrated with wifi ESPN 8266 [1].

Wemos microcontroller is cheaper and more concise with $\mathrm{C}$ programming language. The Wemos programming can be done with Arduino IDE software that has been installed with the ESP8266 library. In the product of the drive-thru market prototype, wemos is used as data transmission from a microcontroller to a web database such as thingspeak or firebase. The android applications to supporting IoT employ Code block programming from MIT App Inventor 2. App Inventor is a software system to create applications on android devices. They are made with graphical visual interactions instead of lines of program code [2].

Based on the classroom observations, the teaching and learning process for Interfacing Engineering, especially on the Internet of Things (IoT) competence and android programming to support IoT still uses common learning media, such as whiteboards, lab sheets, computers, Arduino microcontrollers, and wifi modules ESP 8266. The board and computer media are used by lecturers to explain the material through images, text, and related programs. After the material has been explained, the students are given a lab sheet for practice activities. That learning procedure is ineffective because the students just copying the ready-made program. Moreover, monotonous learning makes the students failed to master algorithms and programming competencies.

Responding to the above problems, the research aims at developing a more applicable learning media for the Interface Engineering course which is a relatively new subject in Mechatronics Engineering Education Study Program, Universitas Negeri Yogyakarta. This study entitled "Developing learning media applications of the Internet of Things in the module of Wemos-based drive-thru market for the Interface Engineering Course".

\section{Method}

The method of this study employed Research and Development approach with the development model of ADDIE according to Branch [4]. This research was divided into two stages, the first was developing hardware of market drive-thru prototype and the second was Android Application software for monitoring the availability of goods on the shelf. This study also developed teaching material in the form of manuals and lab sheets. This research was conducted at the Department of Electrical Engineering Education, Faculty of Engineering, Universitas Negeri Yogyakarta. This research was conducted from May to August 2018. The subjects of this study were the students of the Mechatronics Engineering Education Study Program and the lecturers as material and media experts. The user test was carried out on 16 students who joined the Interface Engineering course. The material and media experts were the lecturers of the Electrical Engineering Education Department, Universitas Negeri Yogyakarta who mastered IoT, microcontroller, and Android programming.

\subsection{Development Procedure}

The development procedure in this study adopted the stages of the Research and Development ( $\mathrm{R}$ \& D) model by Branch [4] called ADDIE that consisted of analyzing, design, develop, implement, 
Journal of Engineering and Applied Technology

Vol. 1, No. 1, March 2020, pp. 11-20

and evaluate. The analysis phase contained four steps to reveal the problems that occur during the learning process and to find the appropriate solutions. It was done by analyzing (a) the learning achievements of the Interface Engineering Course; (b) the suitable learning media; (c) the resources needed to develop the learning media.

The design stage was in the form of (a) objective formulation; (b) tasks design in the form of lab sheets; (c) testing model. The development phase involved the execution of the design stage by creating (a) the learning plan update; (b) hardware in the form of the market drive-thru prototype and Android applications; (c) manuals and lab sheets of IoT application learning media with Wemosbased market drive-thru module; (d) testing; (e) formative validation and revision. The Implementation Phase was carried out in the Mechatronics Engineering Education Study Program, Universitas Negeri Yogyakarta. Finally, the evaluation stage was done by users, media, and material experts after the validation test.

\subsection{Research Instruments}

The research instrument was to measure the extent to which the feasibility level of the learning media applications of the Wemos-based market drives thru the module for the learning medium in the Interface Engineering course. This questionnaire employed the Likert scale model with 5 answer choices, namely "very appropriate", "appropriate", "moderate", "inappropriate", and "very inappropriate" [5]. The instruments were given to the media experts to measure the technical quality of the product, the material experts assessed the quality of content instructional, and structural.

\subsection{Data Analysis Technique}

The data were analyzed through qualitative and quantitative analysis techniques. Qualitative analysis techniques were based on the input, suggestion, and comment from the experts of media and material as the guidance to improve the learning media products. On the other hand, the quantitative data were obtained from the product feasibility based on the questionnaire results from material experts, media experts, and users. The data obtained from the questionnaire were interpreted into qualitative values and converted to scores.

\section{Results and Discussion}

The analysis results showed that: (a) the learning outcomes that must be achieved by students including Wifi / Modem standards to read input data and sending output data to IoT as well as Android program to create applications to support IoT, (b) the need for creative and innovative learning media, such as drive-thru market prototype; (c) the resources to optimally realize the research. In detail, the resource requirements can be seen in Table 1.

Table 1. Identification of resource requirements

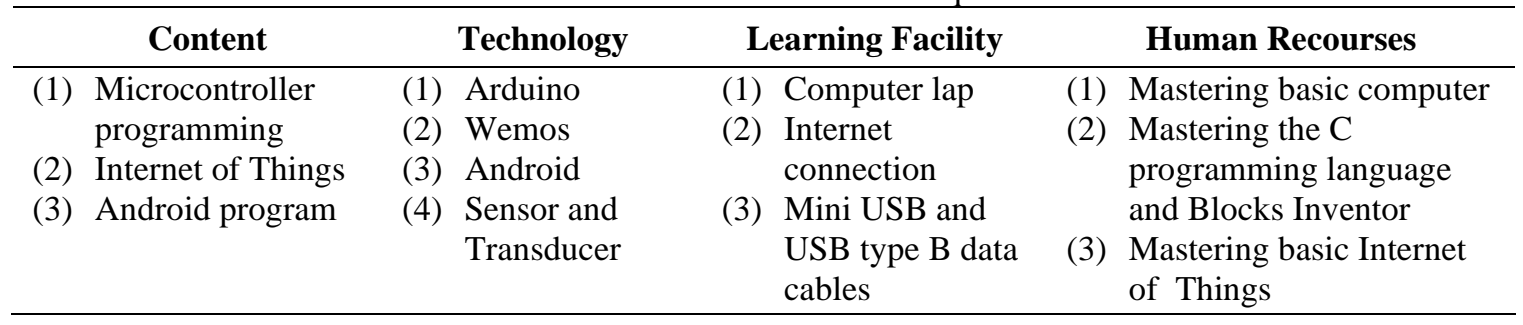

Asnawi, et al., The design and feasibility test of drive-thru market prototype based on Wemos as the learning media of internet c things (IoT) application 
The results of the Design process include (a) learning objectives that were in line with the Semester Learning Plan based on market drive-thru prototype as the learning media of Interface Engineering courses; (b) learning tasks in the form of a spreadsheet; (c) testing strategy including expert judgment, small groups testing and end-user testing.

The results of the Development process involved the development of instructional media which was divided into hardware development (Market DriveThru prototype) and software development (android applications). Fig. 1 below is the rack to place the selling items that rack can be rotated $360^{\circ}$ by users (buyers or drivers) when choosing the items to buy. The rack rotation is controlled by the user by pressing the "up" and "down" buttons. After the buyer decides the product to be purchased, the goods are then put on the conveyor (Fig. 2) to delivered to the cashier. The cashier position is close to the exit gate. The drive-thru market prototype is presented in Fig. 3.

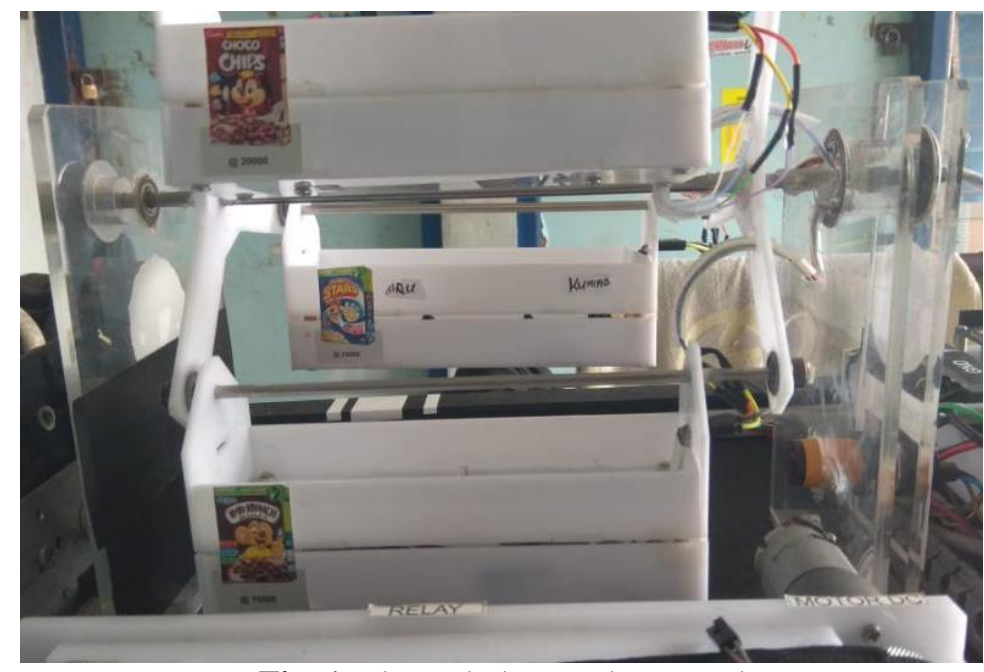

Fig. 1. The rack that can be rotated

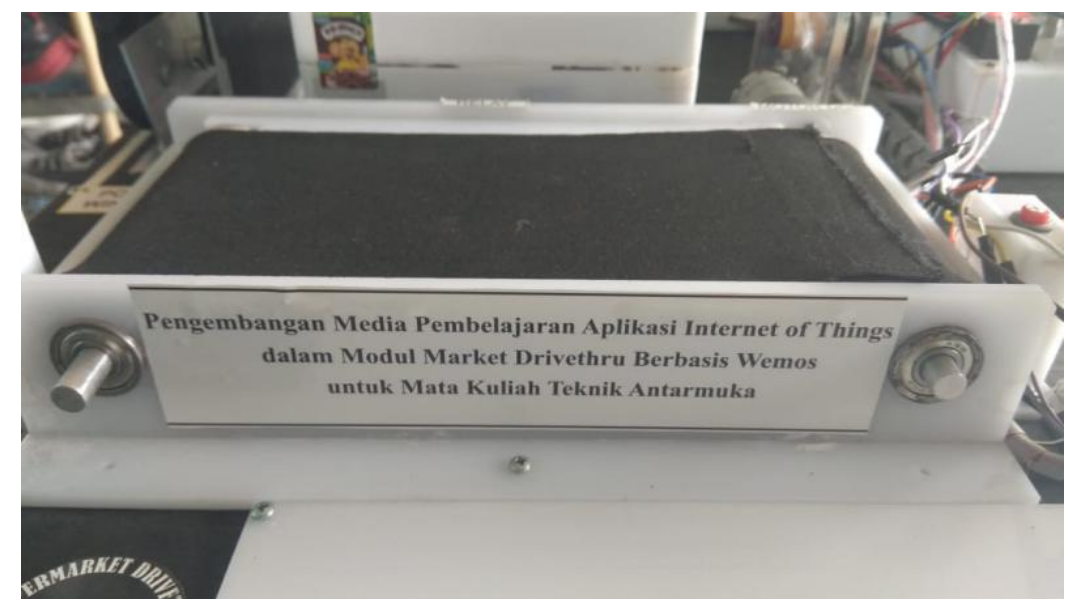

Fig. 2. The conveyor to bring the selected products to the cashier 
Journal of Engineering and Applied Technology

Vol. 1, No. 1, March 2020, pp. 11-20

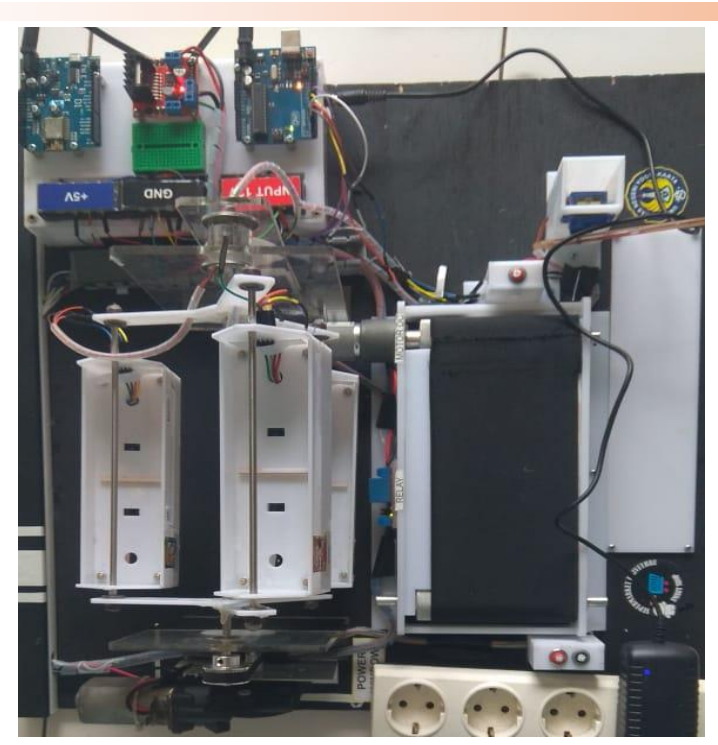

Fig. 3. The prototype of drive-thru Market
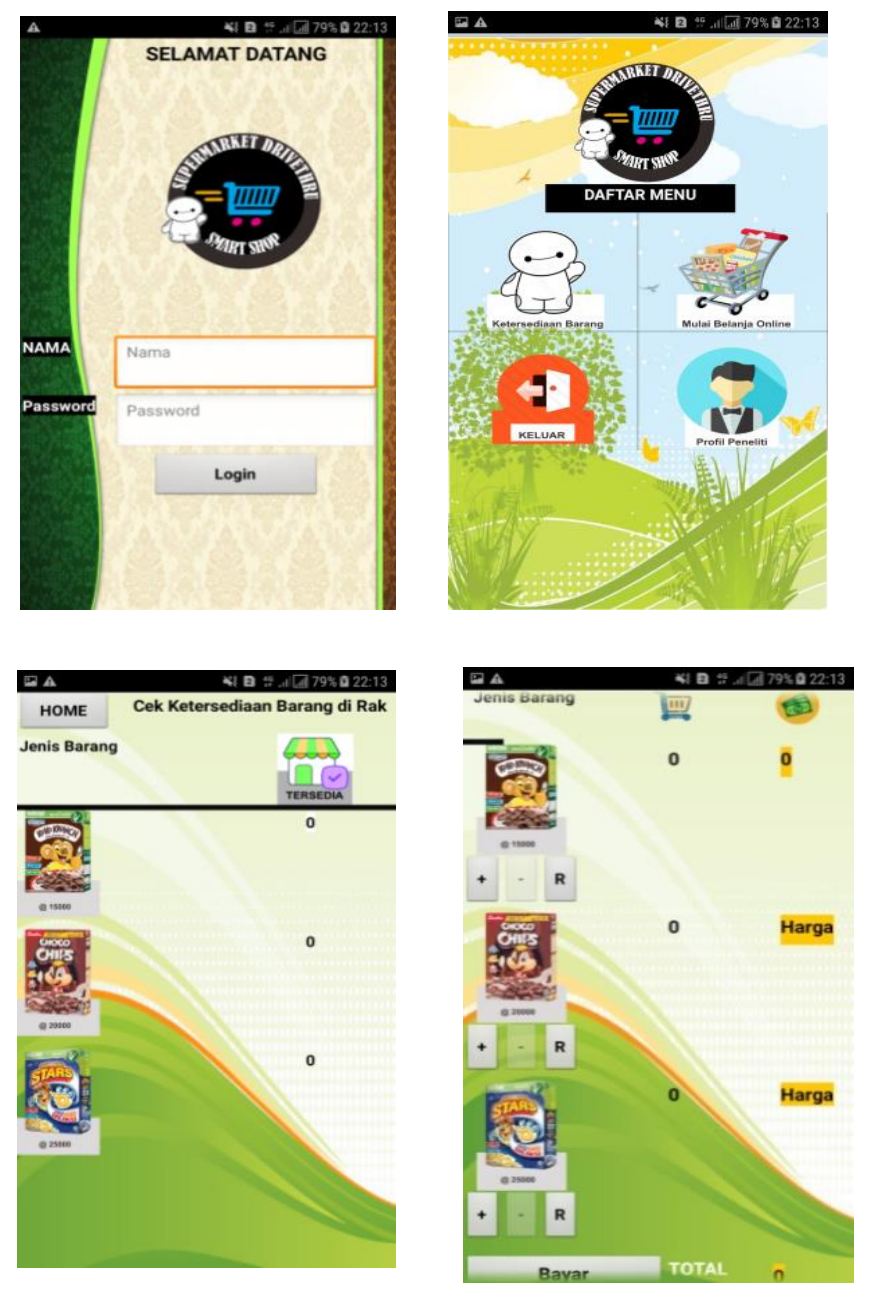

Fig. 4. Android application for the market drive-thru prototype 
Journal of Engineering and Applied Technology

Vol. 1, No. 1, March 2020, pp. 11-20

The next step was testing the product performance including the black box test before the expert judgment. The results of the black box test showed that all functions can work properly based on their respective functions. After that, the hardware test was done to see the performance when it was working. This hardware testing showed that (1) the DC $12 \mathrm{~V}$ power source test functioned normally and $12 \mathrm{v}$ power source that can meet the voltage and current requirements of the prototype product; (2) the power window worked properly by turning right or left with the voltage of $12 \mathrm{v}$; (3) the DC motors and relays run normally with the proper movement of the conveyor; (4) the micro servo can function normally to move the parking bar from the angle of $0^{\circ}$ to $90^{\circ}$ and vice versa; (5) the TCRT5000 sensor testing was normal that can operate the device in places and objects with different brightness levels (see Table 2); (6) the proximity sensor can work normally by detecting objects that were within the adjusted sensor range; (7) the rack/shelf capacity sensor was tested with certain objects on the shelf (see Table 3); (8) the different time of data transmission to the database was influenced by the network connection as presented in Table 4 .

Table 2. TCRT 5000 sensor test

\begin{tabular}{cccc}
\hline No & Room & Object & Sensor Function \\
\hline 1 & Very bright & Bright & Problem encountered \\
2 & Very bright & Dark & Problem encountered \\
3 & Bright & Bright & Normal \\
4 & Bright & Dark & Problem encountered \\
5 & Dark & Bright & Normal \\
6 & Dark & Dark & Problem encountered \\
\hline
\end{tabular}

Table 3. Rack capacity test

\begin{tabular}{ccc}
\hline No & Load & Strength \\
\hline 1 & 200 gram & strong \\
2 & 300 gram & strong \\
3 & 400 gram & strong \\
4 & 500 gram & weak \\
\hline
\end{tabular}

Tabel 4. Data transmission test

\begin{tabular}{ccc}
\hline No & Network & Transmission Speed \\
\hline 1 & $4 \mathrm{G} / \mathrm{LTE}$ & $15-17$ second \\
2 & $3 \mathrm{G} / \mathrm{H}+$ & $17-20$ second \\
3 & $2 \mathrm{G} /$ Edge & Error \\
\hline
\end{tabular}

\subsection{Results of Media Expert Validation}

The media validation test was done by distributing an assessment questionnaire to two experts of instructional media. The aspects contained in the questionnaire consisted of the technical quality of the media. The assessment results from media experts 1 were obtained a total score of 78 . It means the assessment from media expert 1 was $78 \%$ that can be categorized as "Feasible". Meanwhile, the assessment from media experts 2 was 83 or $83 \%$ with the category of "Feasible". 
Journal of Engineering and Applied Technology

Vol. 1, No. 1, March 2020, pp. 11-20

Based on the above data, the learning media of the Wemos-based drive-thru market module can be declared "Feasible "according to both media experts. The analysis results of the media expert assessment are presented in Table 5.

Table 5. Assessment results of the media experts

\begin{tabular}{lccc}
\hline \multirow{2}{*}{ Assessment aspect } & \multicolumn{2}{c}{ Respondent } & Maximum \\
\cline { 2 - 3 } & $\begin{array}{c}\text { Media } \\
\text { Expert 1 }\end{array}$ & $\begin{array}{c}\text { Media } \\
\text { Expert 2 }\end{array}$ & $\begin{array}{c}\text { score } \\
\text { Technical Quality Percentage }\end{array}$ \\
& 78 & 83 & 100 \\
Category & $78 \%$ & $83 \%$ & \\
\hline
\end{tabular}

\subsection{Results of Material Expert Validation}

The material validation test was conducted by distributing an assessment questionnaire to two experts of related materials. The aspects contained in the questionnaire were the quality of content and instructional. Based on the assessment results from material experts 1, it was obtained a score of 31 for its content and 55 for its instructional quality, so the total score was 86 out of 110. It means the assessment from material expert 1 was $78.18 \%$ that can be categorized as "Feasible".

Meanwhile, based on the assessment results from material experts 2, it was obtained a score of 31 for its content and 61 for its instructional quality, so the total score was 93 out of 110. It means the assessment from material expert 1 was $84.55 \%$ that can be categorized as "Very Feasible". Based on the data above, the learning media of the Wemos-based drive-thru market module from the material aspect was declared "Feasible " by the material expert 1 and declared "Very Feasible " by the material experts 2 . The analysis results based on the material expert assessment can be seen in Table 6 .

Table 6. Assessment results of the material experts

\begin{tabular}{lccc}
\hline \multirow{2}{*}{ Assessment aspect } & \multicolumn{2}{c}{ Respondent } & \multirow{2}{*}{$\begin{array}{c}\text { Maximum } \\
\text { score }\end{array}$} \\
\cline { 2 - 3 } & $\begin{array}{c}\text { Material } \\
\text { Expert 1 }\end{array}$ & $\begin{array}{c}\text { Material } \\
\text { Expert 2 }\end{array}$ & \\
\hline Content quality & 31 & 32 & 40 \\
Instructional quality & 55 & 61 & 70 \\
Total Score & 86 & 93 & 96 \\
Percentage & 78.18 & 84.55 & \\
Category & Feasible & Very Feasible & \\
\hline
\end{tabular}

The result of the Implementation phase was done by providing product information to lecturers of Interface Engineering Courses. The information included the overview of the developed media, the construction, the working system, the way to use the media, and the manuals that were completed with lab sheets for practice learning.

\subsection{Users Test Results}

The user test was conducted to reveal the students' responses towards the developed learning media. It contained several assessment aspects, namely: the quality of contents and goals, instructional and technical. The results of the users' test can be seen in Table 7 . 
Journal of Engineering and Applied Technology

Vol. 1, No. 1, March 2020, pp. 11-20

Table 7. The results of the users' test

\begin{tabular}{clcccc}
\hline No & Assessment Aspect & $\begin{array}{c}\text { Total } \\
\text { score }\end{array}$ & $\begin{array}{c}\text { Mean } \\
\text { score }\end{array}$ & Percentage & Category \\
\hline 1 & Contents and goals & 420 & 26.25 & $87.50 \%$ & Very Feasible \\
2 & Instructional & 476 & 29.75 & $85 \%$ & Very Feasible \\
3 & Technical & 896 & 56 & $86,15 \%$ & Very Feasible \\
& Total & 1792 & 112 & $86.15 \%$ & Very Feasible \\
\hline
\end{tabular}

\section{Conclusion}

Based on the research findings, it can be concluded that the learning media of IoT applications can be developed in the form of the drive-thru market prototype with Android support. The prototype consists of racks or shelves, conveyors, and parking bars. Meanwhile, the android application functions to monitor the availability of goods.

The test on the learning media of the Wemos-based market drive-thru module consisted of hardware and software testing. This hardware testing showed that (a) the DC $12 \mathrm{~V}$ power source test functioned normally and $12 \mathrm{v}$ power source that can meet the voltage and current requirements of the prototype product; (b) the power window worked properly by turning right or left with the voltage of $12 \mathrm{v}$; (c) the DC motors and relays run normally with the proper movement of the conveyor; (d) the micro servo can function normally to move the parking bar from the angle of $0^{\circ}$ to $90^{\circ}$ and vice versa; (e) The TCRT5000 sensor can function normally when the light was not too bright and the object color was not too dark; (f) the proximity sensor can function normally by detecting objects within the range of the adjusted sensor; ( $\mathrm{g}$ ) the racks or shelves can only be able to accommodate objects with the maximum weight of 400 grams; (h) the speed of data transmission to the database was 15 to 17 seconds for $4 \mathrm{G}$ networks and 17-20 seconds for $\mathrm{H}+$ networks.

The software testing involving the 6 layer test on Android application showed that the developed media can function properly based on its design plan and function. The feasibility level of the developed learning media was validated by media experts, material experts, and end-users. The media validation results showed that learning media was declared "Feasible" by the media expert 1 with a percentage of $78 \%$, and $83 \%$ from the media expert 2 , respectively.

The results from the material validation showed that the learning media was declared "Feasible" by the material expert 1 with the percentage of 78.18\%, and "Very Feasible" by the material expert 2 with the percentage of $84.55 \%$. On the other hand, the end-user test indicated that the developed learning media was "Very Eligible" with a percentage of $86.15 \%$.

\section{References}

[1] Rochman, H.A dkk. "Sistem Kendali Berbasis Mikrokontroler Menggunakan Protokol MQTT pada Smarthome". Jurnal Pengembangan Teknologi Informasi dan Ilmu Komputer .Vol. 1. No. 6. e-ISSN: 2548-964X. pp 445-455. 2017. 
Journal of Engineering and Applied Technology

Vol. 1, No. 1, March 2020, pp. 11-20

[2] Wahana Komputer. Pemrograman Android dengan APP Inventor. Semarang: ANDI Yogyakarta.2013.

[3] Kadir, A. Panduan Praktis Mempelajari Aplikasi Mikrokontroler dan Pemrogramannya Menggunakan Arduino. Yogyakarta: ANDI. 2013.

[4] Branch, Robert M. Instructional Design: The ADDIE Approach. New York: Springer. 2009.

[5] Widoyoko, E.P. Teknik Penyusunan Instrumen Penelitian. Yogyakarta: Pustaka Pelajar.2016. 